\title{
Defect Study of MgO-CaO Material Doped with $\mathrm{CeO}_{2}$
}

\author{
Han Zhang, Huizhong Zhao, Jinfeng Chen, Jingjie Li, Jun Yu, and Jianhua Nie
}

The Hubei Province Key Laboratory of Ceramics and Refractories, Wuhan University of Science and Technology, 947 Heping Road, Wuhan 430081, China

Correspondence should be addressed to Han Zhang; wustzh@163.com

Received 2 May 2013; Accepted 19 August 2013

Academic Editor: Ho Chang

Copyright (C) 2013 Han Zhang et al. This is an open access article distributed under the Creative Commons Attribution License, which permits unrestricted use, distribution, and reproduction in any medium, provided the original work is properly cited.

$\mathrm{MgO}-\mathrm{CaO}$ refractories were prepared using analytical reagent chemicals of $\mathrm{Ca}(\mathrm{OH})_{2}$ and $\mathrm{Mg}(\mathrm{OH})_{2}$ as starting materials and $\mathrm{CeO}{ }_{2}$ as dopant, then sintered at $1650^{\circ} \mathrm{C}$ for $3 \mathrm{~h}$. The effect of $\mathrm{CeO}_{2}$ powders on the defect of $\mathrm{MgO}-\mathrm{CaO}$ refractories was investigated. The sample characterizations were analyzed by the techniques of XRD and SEM. According to the results, with the addition of $\mathrm{CeO}_{2}$, the lattice constant of $\mathrm{CaO}$ increased, and the bulk density of the samples increased while apparent porosity decreased. The densification of $\mathrm{MgO}-\mathrm{CaO}$ refractories was promoted obviously. In the sintering process, $\mathrm{MgO}$ grains grew faster than $\mathrm{CaO}$, pores at the $\mathrm{MgO}-\mathrm{CaO}$ grain boundaries decreased while pores in the $\mathrm{MgO}$ grains increased gradually, and no pores were observed in the $\mathrm{CaO}$ grains. The nature of the $\mathrm{CeO}_{2}$ promoting densification lies in the substitution and solution with $\mathrm{CaO}$. $\mathrm{Ce}^{4+}$ approaches into $\mathrm{CaO}$ lattices, which enlarges the vacancy concentration of $\mathrm{Ca}^{2+}$ and accelerates the diffusion of $\mathrm{Ca}^{2+}$.

\section{Introduction}

$\mathrm{MgO}-\mathrm{CaO}$ refractories have been widely used in metallurgy industry [1] and cement rotary kilns [2] owing to their excellent properties such as high melting points, excellent thermal shock resistance, and slag corrosion resistance [3]. They have also been considered as one type of chromefree refractories that are suitable for substituting the $\mathrm{MgO}$ $\mathrm{Cr}_{2} \mathrm{O}_{3}$ refractories [4]. Furthermore, $\mathrm{MgO}-\mathrm{CaO}$ refractories are beneficial to removing inclusions from molten steels; thus, they have been considered to be one of the effective refractory types for processing clean steel products $[5,6]$. In recent years, with the increasing demands of molten steel purity, the awareness of environmental protection and resource shortage grows [7], and $\mathrm{MgO}-\mathrm{CaO}$ materials have become one of the attractive steelmaking refractories because of their low cost and high ore reserves [8].

However, the application of $\mathrm{MgO}-\mathrm{CaO}$ refractories has been limited by their poor hydration resistance $[9,10]$. MgO$\mathrm{CaO}$ materials are susceptible to hydration because the free lime in them can react easily with water, volume expansion of the resultant can cause severe damage to the materials.

The hydration resistance of free lime materials can be improved by treating them in a $\mathrm{CO}_{2}$ atmosphere [11] which leads to the formation of a dense maskant on the surface of $\mathrm{CaO}$. Further improvement may be made by adding metal oxides such as $\mathrm{CuO}$ [12], $\mathrm{Fe}_{2} \mathrm{O}_{3}$ [13], and $\mathrm{SiO}_{2}$ [14] to react with lime to form a low-melting point phase or by adding $\mathrm{ZrO}_{2}$ [15-17] to form high-melting stable compounds with $\mathrm{CaO}$. However, the improvements made by using these methods are at the expense of reducing the free lime content, which deteriorates the high-temperature property of $\mathrm{MgO}$ $\mathrm{CaO}$ refractories. It has been reported that the addition of rare earth oxides can appreciably improve the properties of the $\mathrm{MgO}-\mathrm{CaO}$ refractories. However, the mechanisms for the improvements, especially the role played in the improvements by the lattice defects generated as a result of the doping of this type of oxides have not been adequately understood. In the present work, the effect of $\mathrm{CeO}_{2}$ addition on the sintering and microstructure of the $\mathrm{MgO}-\mathrm{CaO}$ refractories are investigated with an aim to delineate the effects of the lattice defects on improving the sintering and hydration resistance of $\mathrm{MgO}-\mathrm{CaO}$ refractories.

\section{Experimental Procedures}

2.1. Raw Materials. In all the experiments, analytical reagent chemicals of $\mathrm{Mg}(\mathrm{OH})_{2}, \mathrm{Ca}(\mathrm{OH})_{2}$, and $\mathrm{CeO}_{2}$ are used as raw materials. Powders of appropriate amounts of $\mathrm{Mg}(\mathrm{OH})_{2}$ and 
$\mathrm{Ca}(\mathrm{OH})_{2}$ were weighed $\left(m_{\mathrm{MgO}}: m_{\mathrm{CaO}}=8: 2\right)$ into a ceramic pot, then mixed in a planetary ball mill for $2 \mathrm{~h}$ at a speed of $180 \mathrm{r} / \mathrm{min}$; the ball-to-powder weight ratio used was $3: 1$. The mixtures obtained were then light-roasted in a muffle furnace at $800^{\circ} \mathrm{C}$ for $30 \mathrm{~min}$ to obtain the $\mathrm{MgO}-\mathrm{CaO}$ powders. 0 $1 \mathrm{wt} \%$ of the $\mathrm{CeO}_{2}$ powder was then dry-mixed with the lightroasted $\mathrm{MgO}-\mathrm{CaO}$ powder. The mixture was then pressed to cylindrical samples of $20 \mathrm{~mm}$ in diameter and $20 \mathrm{~mm}$ in length under a pressure of $150 \mathrm{MPa}$. The samples were heated in an electric furnace at a rate of $3^{\circ} \mathrm{C} / \mathrm{min}$ to $1650^{\circ} \mathrm{C}$ and kept for $3 \mathrm{~h}$, followed by cooling to room temperature in the furnace.

2.2. Characterization of $\mathrm{MgO}-\mathrm{CaO}$ Materials. The sintered samples were characterized by bulk density and apparent porosity measurements, microstructure, and phase composition analyses. The bulk density and apparent porosity were measured by Archimedes' principle using kerosene as an immersion medium under vacuum. The microstructure was analyzed by scanning electron microscopy (SEM, $20 \mathrm{kv}$ ). Phase compositions were determined by X-Ray powder diffraction (XRD, Cu target, $40 \mathrm{kv}$ and $40 \mathrm{~mA}$ ).

\section{Results and Discussion}

3.1. Densification. Figure 1 shows the effect of $\mathrm{CeO}_{2}$ addition on bulk density and apparent porosity of the samples sintered at $1650^{\circ} \mathrm{C}$ for $3 \mathrm{~h}$. It is observed that the bulk density increased gradually and the apparent porosity decreased with the addition of $\mathrm{CeO}_{2}$. The bulk density increased to $3.35 \mathrm{~g} / \mathrm{cm}^{3}$ when the amount of $\mathrm{CeO}_{2}$ added increased to $0.75 \mathrm{wt} \%$. With further addition of $\mathrm{CeO}_{2}$, however, the bulk density slightly decreased. These results indicate that adding small amounts of $\mathrm{CeO}_{2}$ promoted the sintering and densification of $\mathrm{MgO}$ $\mathrm{CaO}$ materials, but this enhancing effect reaches a maximum and starts to decrease when the amount of $\mathrm{CeO}_{2}$ exceeds a certain level.

3.2. XRD Analysis. Figure 2 shows the XRD patterns of samples with and without $\mathrm{CeO}_{2}$ additions. Periclase and lime were the main crystalline phases in all the samples. However, the intensity of diffraction peaks was higher for the samples with $\mathrm{CeO}_{2}$ additions than for the sample without $\mathrm{CeO}_{2}$ addition, indicating that $\mathrm{CeO}_{2}$ promoted the growth of $\mathrm{MgO}$ and $\mathrm{CaO}$ grains, especially for the sample with $0.5 \mathrm{wt} \%$ $\mathrm{CeO}_{2}$ added. The position of the diffraction peaks attributable to the $\mathrm{CaO}\left(\begin{array}{ll}2 & 2\end{array}\right)$ crystallographic was shifted as a result of adding $\mathrm{CeO}_{2}$, suggesting that $\mathrm{Ce}^{4+}$ entered into the $\mathrm{CaO}$ lattice, changing the lattice parameter of $\mathrm{CaO}$. However, no apparent change in the positions of $\mathrm{MgO}$ diffraction peaks was detected.

The $\mathrm{CaO}$ lattice constant of the samples was determined (Table 1) by comparing the peak positions $(2 \theta)$ of the XRD patterns using the least square method.

The lattice constant of $\mathrm{CaO}$ in the samples without $\mathrm{CeO}_{2}$ addition was found to be $4.7978 \AA$, which was in accordance with the lattice constants of pure $\mathrm{CaO}$. Adding $\mathrm{CeO}_{2}$ increased the lattice constant of $\mathrm{CaO}$. When the amount of

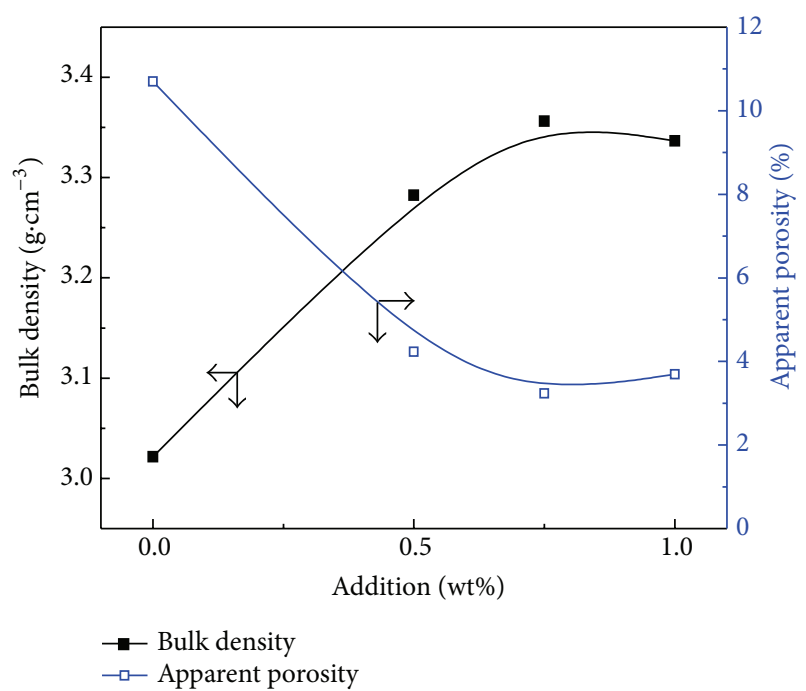

FIgURE 1: Effect of $\mathrm{CeO}_{2}$ addition on bulk density and apparent porosity of samples.

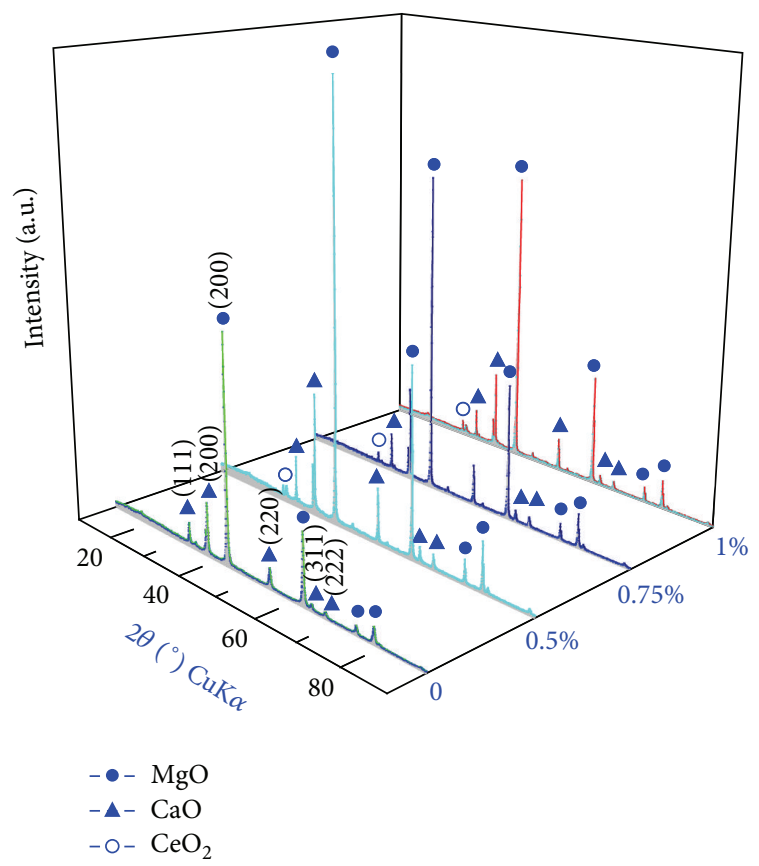

FIGURE 2: XRD patterns of pure and doped $\mathrm{MgO}-\mathrm{CaO}$ samples.

$\mathrm{CeO}_{2}$ added was $0.5 \mathrm{wt} \%$, the lattice constant of $\mathrm{CaO}$ reached the highest point at $a_{\mathrm{CaO}}=4.8232 \AA$. The lattice constants of $\mathrm{CaO}$ decreased with the further increase in $\mathrm{CeO}_{2}$ content, but they were never below the value of the samples without $\mathrm{CeO}_{2}$ addition.

Generally, the solid solution of metal oxides forms mainly by the replacement of positive ions in the solvent. Radius of positive ions directly affects the binding energy of positive and negative ions in ionic crystals and hence influences the solid solubility. When the difference in the radius of positive ions is less than $15 \%$, it is easy to form a solid solution; when the difference is larger than $30 \%$, it is not possible to form a 
TABLE 1: Calculated lattice constant for sintered samples.

\begin{tabular}{|c|c|c|c|c|c|c|c|}
\hline \multirow{2}{*}{ Sample } & \multirow{2}{*}{ Parameters } & \multicolumn{5}{|c|}{$(h k l)$} & \multirow{2}{*}{$a(\AA)$} \\
\hline & & $\left(\begin{array}{lll}1 & 1 & 1\end{array}\right)$ & $\left(\begin{array}{lll}2 & 0 & 0\end{array}\right)$ & $\left(\begin{array}{lll}2 & 2 & 0\end{array}\right)$ & (3 111$)$ & $\left(\begin{array}{lll}2 & 2 & 2\end{array}\right)$ & \\
\hline \multirow{2}{*}{$0 \% \mathrm{CeO}_{2}$} & $2 \theta\left(^{\circ}\right)$ & 32.33 & 37.51 & 54.09 & 64.35 & 67.70 & \multirow{2}{*}{4.7978} \\
\hline & $d(\AA)$ & 2.7681 & 2.3981 & 1.6960 & 1.4471 & 1.3853 & \\
\hline \multirow{2}{*}{$0.5 \mathrm{wt} \% \mathrm{CeO}_{2}$} & $2 \theta\left(^{\circ}\right)$ & 32.34 & 37.50 & 54.04 & 64.36 & 67.54 & \multirow{2}{*}{4.8232} \\
\hline & $d(\AA)$ & 2.7661 & 2.3966 & 1.6961 & 1.4468 & 1.3854 & \\
\hline \multirow{2}{*}{$0.75 \mathrm{wt} \% \mathrm{CeO}_{2}$} & $2 \theta\left({ }^{\circ}\right)$ & 32.37 & 37.52 & 54.07 & 64.36 & 67.60 & \multirow{2}{*}{4.8223} \\
\hline & $d(\AA)$ & 2.7630 & 2.3942 & 1.6953 & 1.4463 & 1.3850 & \\
\hline \multirow{2}{*}{$1 \mathrm{wt} \% \mathrm{CeO}_{2}$} & $2 \theta\left({ }^{\circ}\right)$ & 32.34 & 37.52 & 54.05 & 64.34 & 67.62 & \multirow{2}{*}{4.8161} \\
\hline & $d(\AA)$ & 2.7655 & 2.3961 & 1.6960 & 1.4468 & 1.3852 & \\
\hline
\end{tabular}

solid solution. In this study, the difference in radius between $\mathrm{Ca}^{2+}(0.099 \mathrm{~nm})$ and $\mathrm{Ce}^{4+}(0.097 \mathrm{~nm})$ was about $2.0 \%$, but the difference in radius between $\mathrm{Mg}^{2+}(0.072 \mathrm{~nm})$ and $\mathrm{Ce}^{4+}$ was nearly $26 \%$. Therefore, $\mathrm{CeO}_{2}$ is expected to dissolve easily in $\mathrm{CaO}$ but not in $\mathrm{MgO}$, which is confirmed by the results of XRD analysis.

3.3. SEM Analysis. Figure 3 shows the typical microstructure of the fracture surfaces of samples containing various amounts of $\mathrm{CeO}_{2}$.

The sintered sample without $\mathrm{CeO}_{2}$ addition has more pores and the grains in it were smaller in size compared with the samples with $\mathrm{CeO}_{2}$ additions. Hence, adding $\mathrm{CeO}_{2}$ increased the degree of sintering and densification and facilitated grain growth. $\mathrm{MgO}$ (dark gray) grains grew more rapidly than $\mathrm{CaO}$ (light gray) grains due to the fact that the periclase was the continuous phase surrounding lime and as such the growth of the isolated grains of $\mathrm{CaO}$ was hindered by the difficulty for $\mathrm{Ca}^{2+}$ to diffuse across the matrix during the sintering process. It can be seen that the number of pores decreased progressively as the $\mathrm{CeO}_{2}$ content was increased to $0.75 \mathrm{wt} \%$, but the number increased with further increase in $\mathrm{CeO}_{2}$ content to $1 \mathrm{wt} \%$, which is consistent with the results of Figure 1.

It can be also noted that pores were present at the boundaries between $\mathrm{MgO}$ and $\mathrm{CaO}$ grains or within the $\mathrm{MgO}$ grains; in all the samples no pores were observed within the $\mathrm{CaO}$ grains.

The number of pores at grain boundaries will decrease during the sintering process as a result of grain boundary migration, leading to the formation of bigger pores on crystal surface, which may be eliminated as the sintering process progresses. But with the introduction of $\mathrm{CeO}_{2}$, the number and size of pores in the $\mathrm{MgO}$ grains gradually increased, as the amount of $\mathrm{CeO}_{2}$ doping was increased. This cannot be attributed to the pore evolution in grains, but it may be due to the formation of Schottky lattice defects, which increased the oxygen vacancy concentration in the high-temperature sintering process. With the increasing of additions, the concentration of lattice defects increases and the vacancy formation energy decreases. As a consequence, the oxygen vacancies diffuse, accumulate, and condense to form pores in the grains in the crystal boundary-migration process [18]. Since the pores in the grains can only be eliminated by lattice migration, which is much slower than the crystal boundary migration, it is difficult to eliminate the pores in $\mathrm{MgO}$ grains.

3.4. Effect of Defect Reaction by $\mathrm{CeO}_{2}$ Doping. $\mathrm{CaO}$ and $\mathrm{MgO}$ belong to the cubic system, as it is shown in Figure 4(a).

Figure 4(b) shows the crystal structure doped with $\mathrm{CeO}_{2}$. When $\mathrm{CeO}_{2}$ dissolved into $\mathrm{CaO}$, as the valence of $\mathrm{Ce}^{4+}$ is higher than that of $\mathrm{Ca}^{2+}$ it may cause two kinds of defect reactions as follows:

$$
\begin{aligned}
& \mathrm{O}^{2-} \text { interstitial: } \mathrm{CeO}_{2} \stackrel{\mathrm{Cao}}{\longrightarrow} \mathrm{Ce}_{\mathrm{Ca}}{ }^{.}+\mathrm{O}_{i}{ }^{\prime \prime}+\mathrm{O}_{o}{ }^{\times} \\
& \mathrm{Ca}^{2+} \text { vacancy: } \mathrm{CeO}_{2} \stackrel{\mathrm{Cao}}{\longrightarrow} \mathrm{Ce}_{\mathrm{Ca}}{ }^{.}+\mathrm{V}_{\mathrm{Ca}}{ }^{\prime \prime}+2 \mathrm{O}_{o}{ }^{\times}
\end{aligned}
$$

Solid solution reactions in (1) and (2) comply with the law of conservation of mass and charge. The number of negative ions brought in by $\mathrm{CeO}_{2}$ doping $\left(\mathrm{O}^{2-}: \mathrm{Ce}^{4+}=2: 1\right)$ is more than that of $\mathrm{CaO}\left(\mathrm{O}^{2-}: \mathrm{Ca}^{2+}=1: 1\right)$ causing the surplus of negative ions and the shortage of positive ions. In order to maintain the electroneutrality, additional cation vacancy must be generated when $\mathrm{Ce}^{4+}$ dissolves in the $\mathrm{CaO}$ phase. Hence, $\mathrm{Ca}^{2+}$ vacancy in (2) is the prior modality of charge compensation while defects in $\mathrm{MgO}$ grains mainly come from heat-activation Schottky lattice defects as follows:

$$
0 \rightleftharpoons V_{\mathrm{Mg}}^{\prime \prime}+V_{\mathrm{O}}{ }^{*}
$$

Generally, vacancies in the grains are surrounded by atoms, but atoms are not necessarily surrounded by vacancies. As a result, it is easy for vacancies to diffuse but it is difficult for atoms to diffuse. $\mathrm{MgO}-\mathrm{CaO}$ materials doped with $\mathrm{CeO}_{2}$ enlarge the vacancy concentration of $\mathrm{Ca}^{2+}$. Owing to high symmetry of $\mathrm{CaO}$ crystal structure, the migration energy of $\mathrm{Ca}^{2+}$ vacancy is the same in the six neighboring directions (Figure 4(c)) and migration towards any direction may occur, which contributes to the $\mathrm{Ca}^{2+}$ diffusion. According to the defect reaction, prior modality of charge compensation in $\mathrm{CaO}$ lattice is the vacancy of positive ions, so, no pores occur in the sintering $\mathrm{CaO}$ grains while $\mathrm{O}^{2-}$ vacancy in $\mathrm{MgO}$ grains forms pores in grains.

\section{Conclusions}

(1) The lattice constant of $\mathrm{CaO}$ in $\mathrm{MgO}-\mathrm{CaO}$ materials increases with the addition of $\mathrm{CeO}_{2}$, when the amount 


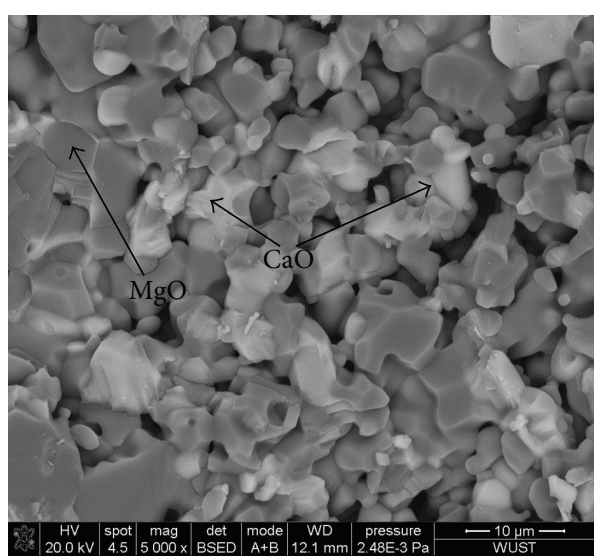

(a)

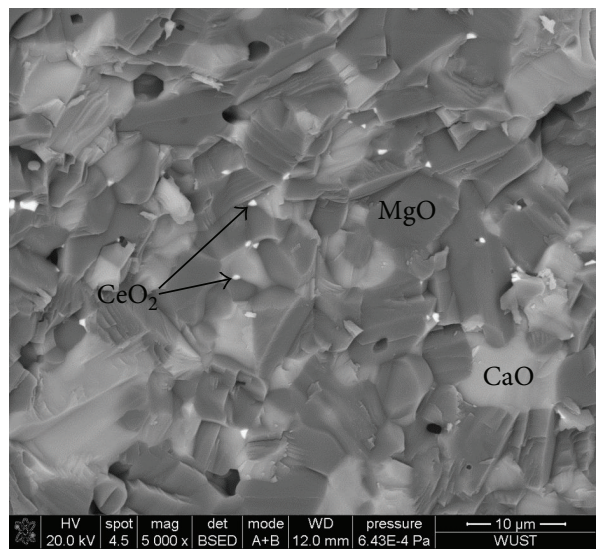

(c)

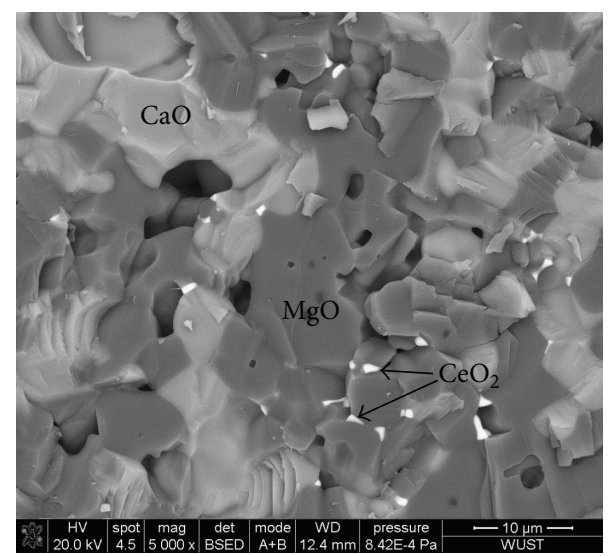

(b)

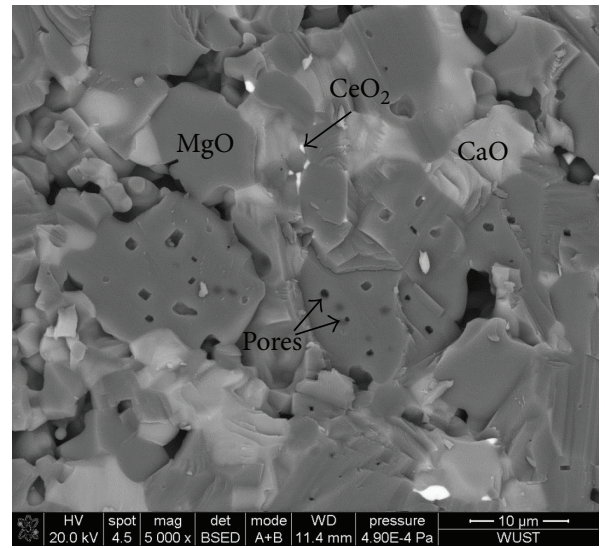

(d)

Figure 3: SEM images of samples: (a) $0 \%$, (b) $0.5 \mathrm{wt} \%$, (c) $0.75 \mathrm{wt} \%$, and (d) $1 \mathrm{wt} \%$.

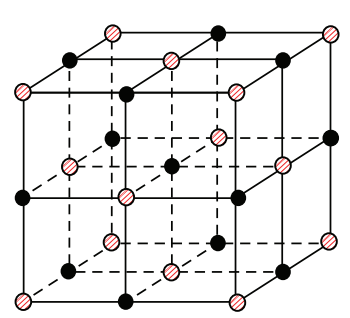

O $\mathrm{O}^{2-}$

- $\mathrm{Ca}^{2+}$

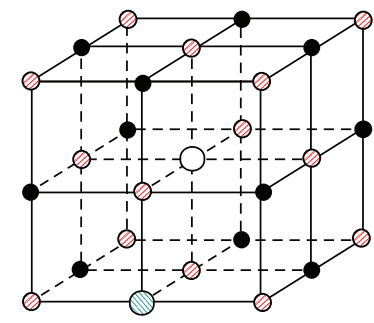

○ $\mathrm{O}^{2-}$

$\bigcirc V_{\mathrm{Ca}}{ }^{\prime \prime}$

(a)
- $\mathrm{Ca}^{2+}$

O $\mathrm{Ce}^{4+}$

(b)

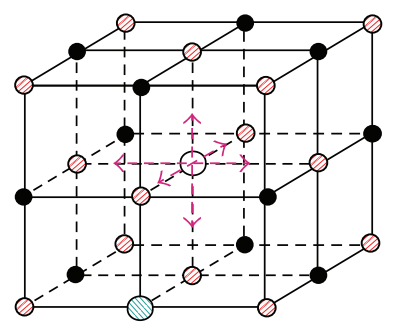

$\bigcirc \mathrm{O}^{2-} \quad-\mathrm{Ca}^{2+}$

$V_{\mathrm{Ca}}^{\prime \prime} \bigcirc \mathrm{Ce}^{4+}$

(c)

Figure 4: Schematic diagram for Crystal structure of $\mathrm{CaO}$. (a) Crystal structure of $\mathrm{CaO}$, (b) crystal structure of $\mathrm{CaO}$ doped with $\mathrm{CeO}_{2}$, and (c) schematic diagram for vacancy migration of $\mathrm{Ca}^{2+}$.

of addition exceeds $0.5 \mathrm{wt} \%$, the lattice constant starts to decrease.

(2) The addition of $\mathrm{CeO}_{2}$ increases the vacancy concentration of $\mathrm{Ca}^{2+}$ and accelerates the diffusion of $\mathrm{Ca}^{2+}$, contributing to the sintering densification of materials. Many pores are formed in the grains of $\mathrm{MgO}$, which mainly originated from the Schottky lattice defects and oxygen vacancy aggregation when the grain boundaries migrate during high-temperature sintering.

\section{Acknowledgment}

This work was supported by the Natural Science Foundation of China (Grant no. 50774057). 


\section{References}

[1] W. E. Lee and R. E. Moore, "Evolution of in situ refractories in the 20th century," Journal of the American Ceramic Society, vol. 81, no. 6, pp. 1385-1410, 1998.

[2] Z. Q. Guo, S. Palco, and M. Rigaud, "Bonding of cement clinker onto doloma-based refractories," Journal of the American Ceramic Society, vol. 88, no. 6, pp. 1481-1487, 2005.

[3] Z. Li, S. Zhang, and W. E. Lee, "Improving the hydration resistance of lime-based refractory materials," International Materials Reviews, vol. 53, no. 1, pp. 1-20, 2008.

[4] M. Rabah and E. M. M. Ewais, "Multi-impregnating pitchbonded Egyptian dolomite refractory brick for application in ladle furnaces," Ceramics International, vol. 35 , no. 2, pp. 813819, 2009.

[5] Y. W. Wei and N. Li, "Refractories for clean steel making," American Ceramic Society Bulletin, vol. 81, no. 5, pp. 32-35, 2002.

[6] X. Zhong, "Looking ahead-a new generation of high performance refractory ceramics," Naihuo Cailiao, vol. 37, no. 1, pp. 1-10, 2003.

[7] L. N. Zhong, B. L. Wu, J. G. Song et al., "Recycling refractory waste," Journal of Functional Materials, vol. 35, supplement, pp. 2615-2618, 2004.

[8] W. Meyer, A. Franchi, G. Buchebner, and M. Willingshofer, "The use of dolomite-carbon-lined ladles for the production of superclean steels," Veitsch-Radex Rundschau, vol. 1998, no. 2, pp. 32-44, 1998.

[9] N. M. Ghoneim, M. A. Mandour, and M. A. Serry, "Phase composition, microstructure and properties of sintered $\mathrm{La}_{2} \mathrm{O}_{3}$ doped lime and dolomite grains," Ceramics International, vol. 16, no. 4, pp. 215-223, 1990.

[10] A. Ghosh and H. S. Tripathi, "Sintering behaviour and hydration resistance of reactive dolomite," Ceramics International, vol. 38, no. 2, pp. 1315-1318, 2012.

[11] M. Chen, N. Wang, J. Yu, and A. Yamaguchi, "Effect of porosity on carbonation and hydration resistance of $\mathrm{CaO}$ materials," Journal of the European Ceramic Society, vol. 27, no. 4, pp. 19531959, 2007.

[12] A. Ghosh, T. K. Bhattacharya, B. Mukherjee, and S. K. Das, "Effect of $\mathrm{CuO}$ addition on the sintering of lime," Ceramics International, vol. 27, no. 2, pp. 201-204, 2001.

[13] H. A. Yeprem, "Effect of iron oxide addition on the hydration resistance and bulk density of doloma," Journal of the European Ceramic Society, vol. 27, no. 2-3, pp. 1651-1655, 2007.

[14] É. Makó, "The effect of quartz content on the mechanical activation of dolomite," Journal of the European Ceramic Society, vol. 27, no. 2-3, pp. 535-540, 2007.

[15] J. L. Rodríguez, M. A. Rodríguez, S. De Aza, and P. Pena, "Reaction sintering of zircon-dolomite mixtures," Journal of the European Ceramic Society, vol. 21, no. 3, pp. 343-354, 2001.

[16] J. Xue, J. H. Tinkler, and R. Dieckmann, "Influence of impurities on the oxygen activity-dependent variation of the oxygen content of a commercial, $\mathrm{CaO}$-doped $\mathrm{ZrO}_{2}$," Solid State Ionics, vol. 166, no. 1-2, pp. 199-205, 2004.

[17] M. Chen, C. Lu, and J. Yu, "Improvement in performance of $\mathrm{MgO}-\mathrm{CaO}$ refractories by addition of nano-sized $\mathrm{ZrO}_{2}$," Journal of the European Ceramic Society, vol. 27, no. 16, pp. 4633-4638, 2007.

[18] J.-K. Yan, G.-Y. Gan, J. Yuan, J.-H. Du, and J.-H. Yi, “Defect chemistry and formation mechanism of pores in undoped $\mathrm{TiO}_{2}$ ceramics," Chinese Journal of Nonferrous Metals, vol. 21, no. 6, pp. 1380-1388, 2011. 

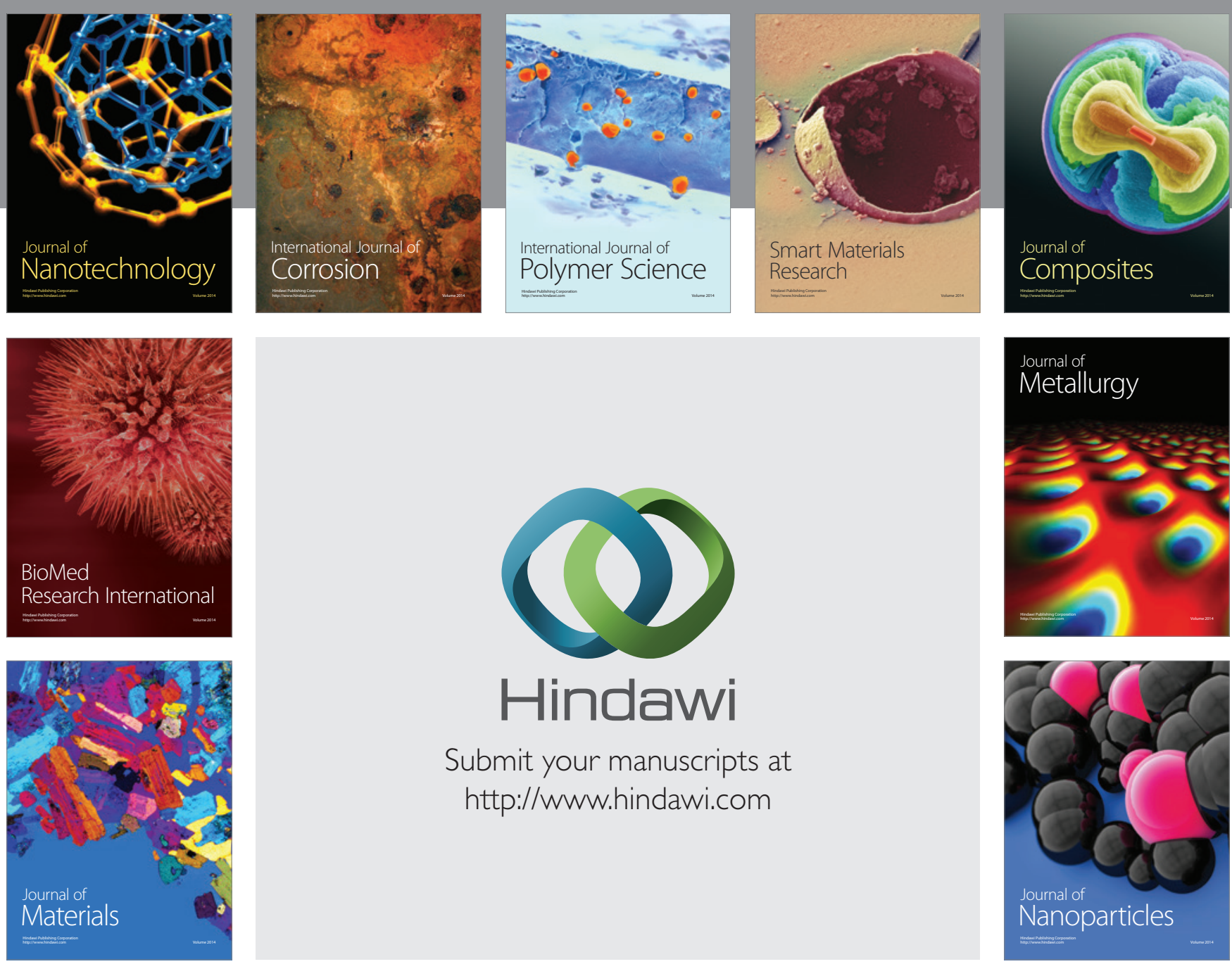

Submit your manuscripts at http://www.hindawi.com
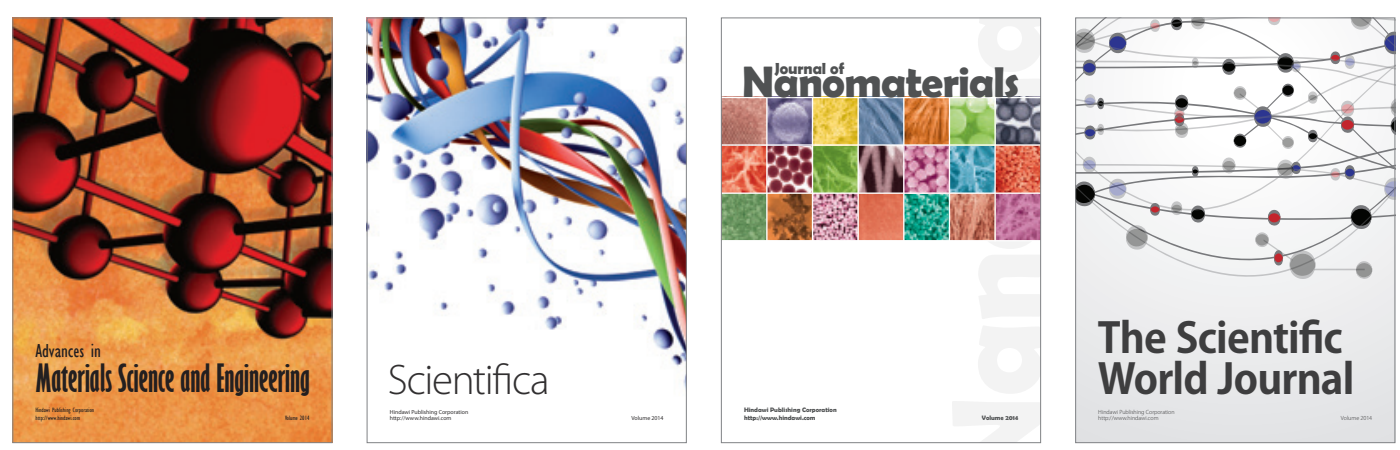

\section{The Scientific World Journal}
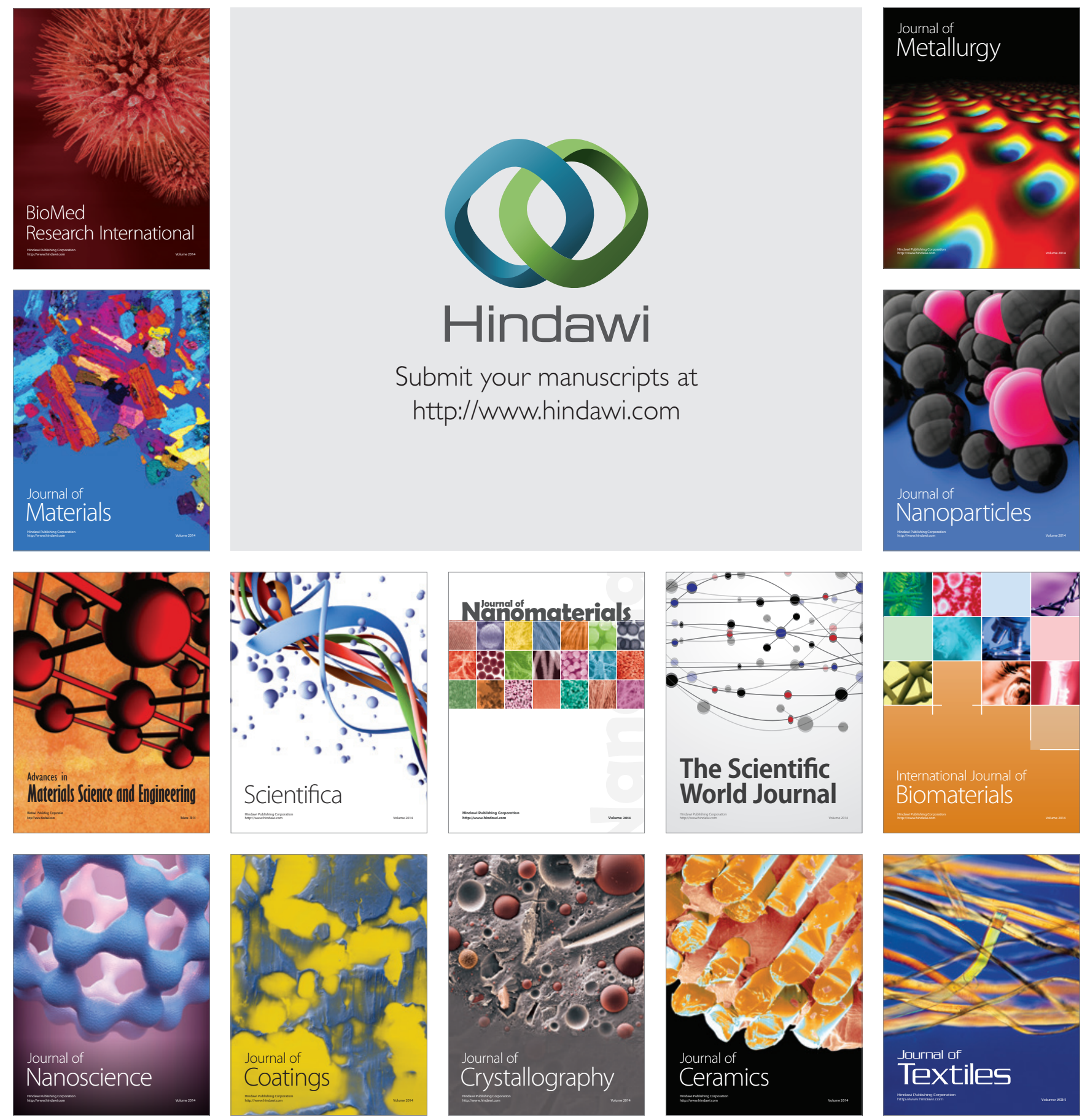